\title{
Pregnancy Outcomes of the Internally Displaced Women in Juba, South Sudan
}

\author{
Sarah Mustafa ${ }^{1,2}$, Projestine S. Muganyizi2 ${ }^{*}$, Anthony Lupai ${ }^{1}$, Belinda S. Balandya ${ }^{2}$ \\ ${ }^{1}$ Juba Teaching Hospital, Juba, Republic of South Sudan \\ ${ }^{2}$ Muhimbili University of Health and Alied Sciences (MUHAS), Dar es Salaam, Tanzania \\ Email: Sarahmustafa6@yahoo.com, *promuga@yahoo.com, lupaianthony@yahoo.com, lindabsoft@gmail.com
}

How to cite this paper: Mustafa, S., Muganyizi, P.S., Lupai, A. and Balandya, B.S. (2019) Pregnancy Outcomes of the Internally Displaced Women in Juba, South Sudan. Open Journal of Obstetrics and Gynecology, 9, 279-291.

https://doi.org/10.4236/ojog.2019.93029

Received: November 12, 2018

Accepted: February 25, 2019

Published: March 1, 2019

Copyright $\odot 2019$ by author(s) and Scientific Research Publishing Inc. This work is licensed under the Creative Commons Attribution International License (CC BY 4.0).

http://creativecommons.org/licenses/by/4.0/

\begin{abstract}
Background: Conflict and displacement substantially affect maternal reproductive health by increasing the risks formorbidity and mortality. However, most literature on pregnancy outcomes is from cross-border refugees and migrants. To date, scanty literature is available on pregnancy outcomes of internally displaced women. South Sudan, with 16 women dying daily is badly affected by internal conflicts of which by the end of December 2013 about 2.2 million people were internally displaced. The aim of this study was to determine pregnancy outcomes of women living in the United Nations House Internally Displaced People (UN IDP) camp and factors associated with poor outcomes. The study was ethically cleared by MUHAS and the Ministry of Health in South Sudan. Methods: A cross sectional study was conducted in UN House IDP Camp in Juba among internally displaced women who attended antenatal services in the camp, from September to November 2016. Among them, women who became pregnant in last 3 years, excluding the index, were interviewed about their immediate past pregnancy experiences. Additionally, the women were interviewed on reproductive health and gender violence matters. Interviews were guided by a structured questionnaire. Data were analyzed using SPSS software version 20. Descriptive and multivariate logistic regression analyses were computed for associations with poor pregnancy outcome. Results: A total of 300 internally displaced women participated in the study. Data for 289 participants were analyzed for poor pregnancy outcome. More than half of the women, 157 (54.3\%), had poor pregnancy outcome. Poor Maternal outcome was established in $47 \%$ of the women and poor fetal outcome in $27.7 \%$. Delivery in IDP camp compared with outside the camp, was independently associated with a 3-fold increase in risk for poor pregnancy outcome, $\mathrm{OR}=2.9$ (95\% CI: 1.47 - 5.56). Conclusion: The prevalence of poor pregnancy outcome is unacceptably high among in-
\end{abstract}


ternally displaced women seeking antenatal services in the IDP camp in Juba and delivery in the camp seems to increase the risk.

\section{Keywords}

Pregnancy Outcome, Maternal Outcome, Internally Displaced, Internal Conflict, Camp, South Sudan

\section{Background}

Displacement refers to the forced movement of people from their locality or their environment due to armed conflict, natural disasters and famine. Conflict and displacement substantially affect maternal reproductive health and increase risk for maternal and neonatal morbidity and mortality. South Sudan has one of the highest maternal mortality rates globally because of pregnancy related complications. The general poor pregnancy outcomes have been attributed among others to the poor infrastructure, lack of access to basic health care, poor education, low family planning method use, lack of reproductive health information, poor transport services and the paucity of qualified midwives [1]. The estimated maternal mortality rate in 2015 was 789 per 100,000 live births which is the fifth highest in the world and threatens the lives of 2.2 million women [2]. South Sudan is continuing to face challenges in meeting maternal, newborn and child health standards. The ongoing instability and population displacement in South Sudan undermines the scope for development, and has damaged infrastructure and caused, low coverage of health services leading to a fragmented health system [1] [2] [3] [4].

Studies conducted among refugees and immigrants of African origin have consistently reported poor pregnancy outcomes. Belihu, et al., who studied pregnancy outcomes of migrants to Australia from Elitrea, Ethiopia, Somalia and Sudan reported more odds of perinatal mortality, small for Gestation Age births, very low birth weight and very preterm babies of these East African Countries compared to mothers born in Australia [5]. Similar poor pregnancy outcomes have been reported by Bakken et al., who compared perinatal outcomes of refugees of Somalia origin with Norwegian women which led to the conclusion that immigrant women from Somalia need more targeted care during pregnancy and childbirth [6]. Poor pregnancy outcomes have also been reported among immigrants within Africa such as that of Burundian refugees in Tanzania [7]. The underlying cause of such poor pregnancy outcomes among cross-border refugees or migrants is not firmly established. However, some studies have attributed the poor pregnancy outcomes with women's socio-cultural and economical backgrounds as well as poor quality of services they receive [8] [9] [10] [11] [12]. The focus of this study was on internally displaced women in South Sudan. It aimed at determining pregnancy out- 
comes of women living in the UN house IDP camp with a focus on the largest IDP in Juba so as to establish the magnitude and factors associated with poor pregnancy outcomes.

\section{Methods}

This cross sectional study was conducted in the United Nation's House for Internally Displaced People (IDP) camp, Juba, South Sudan from September to November, 2016. UN house IDP camp was purposely selected because it was the largest camp in Juba. This camp is under the supervision of the United Nation Mission in South Sudan (UNMISS), UNHCR and International Medical Corp (IMC). The two available Antenatal Clinics in the camp were involved in the survey. All pregnant women who attended the two clinics and who had ever become pregnant prior to the index one but within past 3 years (counted from the beginning of internal conflicts, 2013) were eligible for inclusion. Based on the number of antenatal registries per clinic, it was agreed to include in the study every second woman who registered to each of the clinics such that the maximum of 10 interviews a day could be realized per clinic. Once an eligible woman was identified, she was informed about the study and if consented to participate, she was asked to sign the consent form.

Mothers who consented to participate were interviewed face to face in Arabic language. All interviews were conducted in a private room offered by the clinics in order to promote confidentiality. Interviews were conducted by three data collectors using a tool with mostly structured questionnaires and few semi-structured items. This tool involved general socio-demographic information about the woman, obstetric history with attention to the immediate past pregnancy, family planning choices and use before conception and some standard questions on Gender violence that have been used by other international organizations in East African context. The tool was available in Arabic and English languages. This tool was pre-tested before applying in the field and the process of data collection was supervised by the Principle Investigator.

\subsection{Sample Size Determination}

In calculating the sample, a $22.4 \%$ prevalence of poor pregnancy outcome was assumed based on the study in the Tanzania based refugee camps [7]. With the assumptions 95\% confidence interval, 5\% marginal error and $80 \%$ power, the calculated sample size was 296 . Considering $10 \%$ possible non respondents, the final sample size estimated was 300 .

\subsection{Data Analysis Procedure}

Data were entered into EPI data software program cleaned and coded, then transferred to SPSS software version 20 for analysis. Descriptive statistics were summarized by using frequencies and proportions. A poor pregnancy outcome was determined if the reference pregnancy ended up in any outcome other than 
a term healthy baby at five minutes (i.e., miscarried, intrauterine fetal death, Stillbirth or Apgar score lower than 7 at 5 minutes and premature delivery) or if the woman gave birth to a baby weighing less than $2500 \mathrm{~g}$, or if the woman was diagnosed with a condition known to cause direct or indirect maternal deaths antenatal or immediately postnatal. A good pregnancy outcome was defined by the absence of any of the features mentioned under poor pregnancy outcome. This pregnancy outcome variable was thus, a composite variable whose outcome was further sub-classified into fetal and maternal outcomes depending on who is primarily affected. The association between the independent variables and the outcome (pregnancy outcome) was determined using Pearson Chi Square test. All variables with a significant association with Maternal or Fetal outcomes and those with a pre-determined p-value less than 0.05 on Bivariate analysis for the composite variables were then entered into Multivariate Analyses in order to determine variables that were independently associated with poor pregnancy outcome which is the primary objective. In all statistics, a p-value of less than 0.05 was taken as significant.

\section{Results}

\subsection{Socio-Demographic Characteristics of Study Participants}

A total of 300 internally displaced women were recruited and completed their interviews. Their mean age was 24.9 ( \pm 3.6 years) with the majority $(81 \%)$ belonging to 21 - 30 year age group. Most women 270 (90\%) were married and more than half of all the women, 177 (59.1\%), had no formal education. In total, $70(23.3 \%)$ reported gender violence of different forms during the reference pregnancy (Table 1 ).

Among the 300 study women, pregnancy outcomes of 289 (96.3\%) was established. Data were insufficient to allow assignment to either poor or good outcome for 11 women. Among the 289 women with all data available, the immediate past pregnancy outcome was poor in 157 (54.3\%). A total of 296 (98.7\%) women had data sufficient to analyze Fetal outcomes and, among them 214 (72.3\%) had good fetal outcome and $82(27.7 \%)$ had poor fetal outcome. Likewise, $257(85.7 \%)$ women had sufficient data to analyze maternal outcome and, among them 152 (59.1\%) had good outcome and 105 (40.9\%) had poor outcome.

From Table 2, among the tested potential risk factors only increasing maternal age $(\mathrm{p}<0.001)$, and delivery in the IDI camp $(\mathrm{p}=0.04)$ were significantly associated with poor maternal outcome.

Poor fetal outcome was associated with maternal age, marital status, occupation, parity and whether the pregnancy was planned or not (Table 3).

Poor pregnancy outcome is a composite variable for Maternal and Fetal outcomes whose analysis is presented in Table 4.

On bivariate analysis, being married was associated with $66 \%$ reduction in risk for poor pregnancy outcome $[\mathrm{OR}=0.34(95 \% \mathrm{CI}: 0.14-0.83)]$, and delivery in 
Table 1. Frequency of socio-demographic characteristics of women attending antenatal services at Juba IDP Camp.

\begin{tabular}{|c|c|c|}
\hline Characteristics & Frequency $\mathrm{N}=300$ & Percentage \\
\hline \multicolumn{3}{|l|}{ Age (years) } \\
\hline $15-20$ & 48 & 16 \\
\hline $21-25$ & 107 & 35.7 \\
\hline $26-30$ & 136 & 45.3 \\
\hline $31+$ & 9 & 3 \\
\hline \multicolumn{3}{|l|}{ Marital status } \\
\hline Single & 22 & 7.3 \\
\hline married & 270 & 90.1 \\
\hline divorced & 4 & 1.3 \\
\hline separated & 3 & 1 \\
\hline widow & 1 & 0.3 \\
\hline \multicolumn{3}{|l|}{ Highest Education } \\
\hline Informal & 177 & 59.1 \\
\hline Primary education & 67 & 22.3 \\
\hline Secondary education & 49 & 16.3 \\
\hline University & 7 & 2.3 \\
\hline \multicolumn{3}{|l|}{ Occupation } \\
\hline Employed & 4 & 1.3 \\
\hline Business & 19 & 6.3 \\
\hline housewife & 261 & 87 \\
\hline Students & 16 & 5.3 \\
\hline \multicolumn{3}{|l|}{ Parity } \\
\hline 0 & 16 & 5.3 \\
\hline $1-2$ & 166 & 55.3 \\
\hline $3-4$ & 110 & 36.7 \\
\hline $5+$ & 8 & 2.7 \\
\hline \multicolumn{3}{|l|}{ Pregnancy Planned } \\
\hline Yes & 69 & 23 \\
\hline No & 231 & 77 \\
\hline \multicolumn{3}{|c|}{ Contraception Method Used } \\
\hline Yes & 69 & 23 \\
\hline No & 231 & 77 \\
\hline \multicolumn{3}{|l|}{ Duration in Camp } \\
\hline 1 - 2 years & 177 & 59 \\
\hline$>2$ years & 123 & 41 \\
\hline \multicolumn{3}{|c|}{ Gender Violence during pregnancy } \\
\hline Yes & 70 & 23.3 \\
\hline No & 230 & 76.7 \\
\hline
\end{tabular}


Table 2. Association of maternal characteristics with poor maternal outcome, data presented as $\mathrm{n}(\%)$.

\begin{tabular}{|c|c|c|c|}
\hline \multirow[b]{2}{*}{ Characteristics } & \multicolumn{2}{|c|}{ Maternal Outcome } & \multirow[b]{2}{*}{$\mathrm{p}$-Value } \\
\hline & $\begin{array}{l}\text { Poor, } \\
\mathrm{N}=105\end{array}$ & $\begin{array}{l}\text { Good, } \\
N=152\end{array}$ & \\
\hline \multicolumn{4}{|l|}{$\begin{array}{c}\text { Age } \\
\text { (years) }\end{array}$} \\
\hline $15-20$ & $10(9.5)$ & $21(13.8)$ & \multirow{3}{*}{$<0.001$} \\
\hline $\begin{array}{l}21-25 \\
26-30\end{array}$ & $36(34.3)$ & $\begin{array}{l}55(36.2) \\
73(48.0)\end{array}$ & \\
\hline $31+$ & $5(4.8)$ & $3(2.0)$ & \\
\hline \multicolumn{4}{|l|}{ Current } \\
\hline $\begin{array}{c}\text { Married } \\
\text { Unmarried }\end{array}$ & $\begin{array}{l}99(94.3) \\
6(5.7)\end{array}$ & $\begin{array}{c}141(92.8) \\
11(7.2)\end{array}$ & 0.8 \\
\hline \multicolumn{4}{|l|}{ Education } \\
\hline Informal & $56(53.3)$ & $84(55.3)$ & \multirow{3}{*}{0.843} \\
\hline Primary & $38(36.2)$ & $50(32.9)$ & \\
\hline Secondary or Higher & $11(10.5)$ & $18(11.8)$ & \\
\hline \multicolumn{4}{|l|}{ Occupation } \\
\hline Income generating & $5(4.9)$ & $12(8.1)$ & \multirow[b]{2}{*}{0.322} \\
\hline Not Income generating & $97(95.1)$ & $136(91.9)$ & \\
\hline \multicolumn{3}{|l|}{ Pregnancy } & Planned \\
\hline $\begin{array}{l}\text { Yes } \\
\text { No }\end{array}$ & $81(77.1)$ & $\begin{array}{l}118(77.6) \\
34(22.4)\end{array}$ & 1 \\
\hline \multicolumn{4}{|l|}{ Contraception } \\
\hline $\begin{array}{l}\text { Yes } \\
\text { No }\end{array}$ & $\begin{array}{l}25(23.8) \\
80(76.2)\end{array}$ & $\begin{array}{c}40(26.3) \\
112(73.7)\end{array}$ & 0.665 \\
\hline \multicolumn{4}{|l|}{$\begin{array}{l}\text { Delivered } \\
\text { in Camp }\end{array}$} \\
\hline $\begin{array}{l}\text { Yes } \\
\text { No }\end{array}$ & $15(14.3)$ & $\begin{array}{l}114(75.0) \\
38(25.0)\end{array}$ & 0.042 \\
\hline \multicolumn{4}{|l|}{$\begin{array}{l}\text { Gender Violence } \\
\text { during pregnancy }\end{array}$} \\
\hline Yes & $29(27.6)$ & $42(20.4)$ & 0.181 \\
\hline
\end{tabular}


Table 3. Association of maternal characteristics with poor fetal outcome, data presented as $\mathrm{n}(\%)$.

\begin{tabular}{|c|c|c|c|}
\hline \multirow{2}{*}{ Characteristics } & \multicolumn{2}{|c|}{ Fetal Outcome } & \multirow{2}{*}{ p-Value } \\
\hline & Poor, $\mathrm{N}=82$ & Good, $N=214$ & \\
\hline \multicolumn{4}{|l|}{ Age (years) } \\
\hline $15-20$ & $20(24.4)$ & $28(13.1)$ & $<0.001$ \\
\hline $21-25$ & $28(34.1)$ & $76(35.5)$ & \\
\hline $26-30$ & $32(39.0)$ & $103(48.1)$ & \\
\hline $31+$ & $2(2.4)$ & $7(3.3)$ & \\
\hline \multicolumn{4}{|l|}{ Current Marital Status } \\
\hline Married & $64(78.0)$ & $202(94.4)$ & $<0.001$ \\
\hline Unmarried & $18(22.0)$ & $12(5.6)$ & \\
\hline \multicolumn{4}{|l|}{ Highest Education } \\
\hline Informal & $37(45.1)$ & $120(56.1)$ & \\
\hline Primary & $33(40.2)$ & $69(32.2)$ & \\
\hline Secondary or Higher & $12(14.6)$ & $25(11.7)$ & 0.24 \\
\hline \multicolumn{4}{|l|}{ Occupation } \\
\hline Income generating & $13(17.8)$ & $10(4.8)$ & \\
\hline Not Income generating & $60(82.2)$ & $197(95.2)$ & 0.002 \\
\hline Parity & $16(19.5)$ & $0(0)$ & \\
\hline 0 & $43(52.4)$ & $120(56.1)$ & \\
\hline $1-2$ & $19(23.2)$ & $90(42.1)$ & $<0.001$ \\
\hline $3-4$ & $4(4.9)$ & $4(1.9)$ & \\
\hline \multicolumn{4}{|l|}{$5+$} \\
\hline \multicolumn{4}{|l|}{ Pregnancy Planned } \\
\hline Yes & $51(62.2)$ & $169(79.0)$ & \\
\hline No & $31(37.8)$ & $45(21.0)$ & 0.005 \\
\hline \multicolumn{4}{|l|}{ Contraception Method Used } \\
\hline Yes & $16(19.5)$ & $53(24.8)$ & \\
\hline No & $66(80.5)$ & $161(75.2)$ & 0.362 \\
\hline \multicolumn{4}{|l|}{ Delivered in Camp } \\
\hline Yes & $70(85.4)$ & $169(79.0)$ & \\
\hline No & $12(14.6)$ & $45(21.4)$ & 0.251 \\
\hline \multicolumn{4}{|c|}{ Gender Violence during pregnancy } \\
\hline Yes & $25(30.5)$ & $45(21.0)$ & \\
\hline No & $57(69.5)$ & $169(79.0)$ & 0.094 \\
\hline
\end{tabular}


Table 4. Bivariate and multivariate analyses of the potential risk factors for poor pregnancy outcome at Juba IDP Camp, South Sudan.

\begin{tabular}{|c|c|c|c|c|}
\hline Characteristics & $\begin{array}{c}\text { Poor Pregnancy } \\
\text { Outcome, N = } 157\end{array}$ & COR, 95\% CI & AOR, 95\% CI & P-value \\
\hline \multicolumn{5}{|l|}{ Age } \\
\hline $15-20$ & $26(16.6)$ & $1.1(0.56-2.12)$ & $2.19(0.88-5.49)$ & 0.09 \\
\hline $21-25$ & $50(31.8)$ & $1.38(0.82-2.30)$ & $2.0(1.03-3.74)$ & \\
\hline $26+$ & $51(51.6)$ & 1 & 1 & \\
\hline \multicolumn{5}{|l|}{ Parity } \\
\hline 2 or less & $101(64.3)$ & $1.23(0.29-5.34)$ & $0.77(0.15-3.85)$ & 0.06 \\
\hline 3 to 4 & $51(32.5)$ & $1.76(0.40-7.76)$ & $1.66(0.35-7.93)$ & \\
\hline $5+$ & $5(3.2)$ & 1 & 1 & \\
\hline \multicolumn{5}{|c|}{ Current Marital status } \\
\hline Married & $135(86.0)$ & $0.34(0.14-0.83)$ & $0.41(0.12-1.43)$ & 0.16 \\
\hline Unmarried & $22(14.0)$ & & & \\
\hline \multicolumn{5}{|l|}{ Occupation } \\
\hline Income source & $15(10.2)$ & $1.95(0.77-4.94)$ & $1.19(0.41-3.48)$ & 0.75 \\
\hline No income source & $132(89.8)$ & & & \\
\hline \multicolumn{5}{|l|}{ Pregnancy desired } \\
\hline Yes & $112(71.3)$ & $0.73(0.43-1.25)$ & $0.97(0.50-1.90)$ & 0.93 \\
\hline No & $45(28.7)$ & & & \\
\hline \multicolumn{5}{|l|}{ Place of delivery } \\
\hline Camp & $139(88.5)$ & $3.0(1.62-5.60)$ & $2.9(1.47-5.56)$ & 0.002 \\
\hline Outside Camp & $18(11.5)$ & & & \\
\hline \multicolumn{5}{|l|}{ Gender violence } \\
\hline Yes & $39(24.8)$ & $1.28(0.74-2.24)$ & $1.35(0.73-2.48)$ & 0.34 \\
\hline No & $118(75.2)$ & & & \\
\hline
\end{tabular}

the camp was associated with a 3-fold increased risk for poor pregnancy outcome compared with delivery outside the camp. Other factors were not significantly associated with poor pregnancy outcome. After, controlling for confounders, the independent risk for poor pregnancy outcome remained delivery in the IDI camp with almost 3-fold increased risk for poor outcome, $[\mathrm{OR}=2.9$, (95\% CI: 1.47 - 5.56)], $\mathrm{p}=0.002$ (Table 4).

\section{Discussion}

Pregnancy outcomes of African and non-African immigrants in countries within and outside the continent are generally reported to be poor [5] [6] [9] [11] [12]. The poor pregnancy outcomes of immigrant women are often attributed to their 
social background complexity, communication barriers, poor infrastructure and others of the like. Many of these reasons are attributable to their existence in a foreign socio-cultural environment [8] [9] [10] [13] [14]. The current study was conducted in South Sudan where social conflicts have led to many people being displaced internally. At the time of conducting this study, there was scanty literature on pregnancy outcomes for internally displaced women who may not share similar challenges with cross-border immigrants and refugees.

Most women in this study were illiterate young mothers who did not plan their pregnancies. Majority had no own source of income and almost a quarter of them had self experienced some forms of gender violence during pregnancy. A similar background has been almost consistently reported by others in studies conducted among refugees and immigrants of African origin [5] [6] [13] [15], probably being partly contributed by the persistence of internal social conflicts and poor socio-economic conditions. Notwithstanding the origin of this poor socio-economical background its contribution to poor pregnancy outcomes was obvious in the current study as most of the indicator factors were either associated with poor maternal or fetal outcomes.

In the current study, more than half of women reported poor pregnancy outcome in their immediate past pregnancy which was mainly contributed by the high proportions of women suffering from conditions that often lead to direct or indirect maternal and perinatal deaths. These results are consistent with those of the study that compared pregnancy outcomes of multi-country immigrants to Australia whereby women from Eritrea and Sudan exhibited disproportionately increased risks for adverse pregnancy outcomes particularly with markedly increased risks for low birth weight, preterm birth and perinatal mortality [5]. In additional to perinatal risks, this study shows a high proportion of women with poor maternal outcomes whereby approximately half of the women reported adverse maternal conditions. Within Africa, a similar situation was reported by Jamieson et al., among Burundian refugees in Tanzania whereby prior socio-economic status, malaria infection and obstetric factors were associated with the poor outcome [7]. Based on these findings, internally displaced women in South Sudan face high rates of poor pregnancy outcomes as cross-border refugees and migrants.

Studies on immigrants and refugees often compare their pregnancy outcomes with the local population [5] [6] [12] or rarely their populations of origin [10]. This study, in addition to findings similar to cross-border immigrants and refugees, has found a 3-fold increased risk for poor pregnancy outcome for women whose deliveries were attended in the IDP camp notwithstanding their obstetric history, source of income, maternal age and other background factors that have been linked with increased risk for poor outcomes [7]. It is therefore suggested by the current findings, that poor pregnancy outcomes among women in IDP camp in Juba is mainly contingent on factors within the camp rather than the socio-cultural background of the women. This statement, however, does not 
underrate the importance of socio-cultural and economical factors on poor pregnancy outcomes in the study population. In fact this study has indicated the association of several socio-economic, obstetric and reproductive health factors with poor fetal and maternal outcomes. However, when these common problems to most displaced women were controlled for, delivery in the camp becomes an outstanding reason for the poor pregnancy outcome.

These findings call for the Camp Management in Juba to review and eliminate bottlenecks that hinder quality Maternal, Newborn and Child health services, and for the government to improve the overall socio-economic standards of the population. A study in Thailand, where literacy rate was as low as in Juba among refugees and migrants at the baseline, concluded after a period of interventions, that significant reduction in poor pregnancy outcome over time was not driven by changes in literacy rates but rather by improved access to early diagnosis and treatment of malaria and delivery with skilled birth attendants [15]. This example can be replicated in South Sudan.

The strength of this study was to reach and conduct interviews with internally displaced women in the context of social conflicts and war in Juba at the time when literature on pregnancy outcomes of such women was generally scanty. The use of Arabic and English languages by the Native female investigator and interviewers should have minimized language and social barriers often encountered during studies or interventions among refugees and migrants of African origin [6] [9]. An important limitation of this study is the recall bias for women who could not recall what happened in the immediate past pregnancy. This limitation was mitigated by confining to pregnancies that occurred within a relatively short time of last 3 years. The results of this study call for policy makers and program Managers in South Sudan and Particularly the IDP camp in Juba to review the quality of $\mathrm{MNCH}$ services in order to improve Maternal and Newborn outcomes.

\section{Conclusion}

Poor pregnancy outcome is common among internally displaced women in Juba, IDP camp. Although multiple socio-demographic factors were associated with poor pregnancy outcome, the association with delivery in IDP camp is independent of all others. Strengthening the quality of $\mathrm{MNCH}$ services in IDP camp and the general socio-economic conditions of the population are necessary for improved outcome.

\section{Declarations}

\section{Ethics Approval and Consent to Participate}

Ethical approval of this study was granted from Muhimbili University of health and Allied Sciences (MUHAS) Research and Ethical committee and from the Directorate of Monitoring, Evaluation and Research of the Ministry of Health, Republic of South Sudan. Permission to conduct the study in the camp was 
granted by UNMISS and IMC. All participants gave written consent to participate in the study.

\section{Consent for Publication}

A written permission to publish this paper was given by the Ministry of Health, Republic of South Sudan.

\section{Availability of Data and Material}

The datasets used during the current study are available from the corresponding author on reasonable request and upon approval by the Muhimbili University of Health and Allied Sciences.

\section{Funding}

The principle investigator received a small support funding from the University to assist in data collection.

\section{Author Contributions}

SM participated in development of the idea, writing the proposal, field work, analysis, writing the manuscript. PSM and AL improved the idea, reviewed the proposal, helped in data analysis and writing the manuscript. BSB reviewed the proposal, participated in interpreting data results and writing the manuscript. All approved the manuscript for publication.

\section{Acknowledgements}

The Authors of this paper acknowledge academic members in the department of Obstetrics and Gynecology, Muhimbili University of Health and Allied Sciences for their valued comments that helped to shape the study.

\section{Conflicts of Interest}

The authors declare no conflicts of interest regarding the publication of this paper.

\section{References}

[1] Mugo, N.S., Dibley, M.J., Damundu, E.Y. and Alam, A. (2018) The System Here Isn't on Patients' Side-Perspectives of Women and Men on the Barriers to Accessing and Utilizing Maternal Healthcare Services in South Sudan. BMC Health Services Research, 18, 10. https://doi.org/10.1186/s12913-017-2788-9

[2] Mugo, N., Zwi, A.B., Botfield, J.R., et al. (2015) Maternal and Child Health in South Sudan: Priorities for the Post-2015 Agenda. SAGE Open, 14. https://doi.org/10.1177/2158244015581190

[3] Mugo, N.S., Agho, K.E. and Dibley, M.J. (2016) Risk Factors for Non-Use of Skilled Birth Attendants: Analysis of South Sudan Household Survey, 2010. Maternal and Child Health Journal, 20, 1266-1279. https://doi.org/10.1007/s10995-016-1928-x

[4] Mugo, N.S., Dibley, M.J. and Agho, K.E. (2015) Prevalence and Risk Factors for 
Non-Use of Antenatal Care Visits: Analysis of the 2010 South Sudan Household Survey. BMC Pregnancy Childbirth, 15, 68.

https://doi.org/10.1186/s12884-015-0491-6

[5] Belihu, F.B., Davey, M.A. and Small, R. (2016) Perinatal Health Outcomes of East African Immigrant Populations in Victoria, Australia: A Population Based Study. BMC Pregnancy Childbirth, 16, 86. https://doi.org/10.1186/s12884-016-0886-Z

[6] Bakken, K.S., Skjeldal, O.H. and Stray-Pedersen, B. (2015) Immigrants from Conflict-Zone Countries: An Observational Comparison Study of Obstetric Outcomes in a Low-Risk Maternity Ward in Norway. BMC Pregnancy Childbirth, 15, 163. https://doi.org/10.1186/s12884-015-0603-3

[7] Jamieson, D.J., Meikle, S.F., Hillis, S.D., Mtsuko, D., Mawji, S. and Duerr, A. (2000) An Evaluation of Poor Pregnancy Outcomes among Burundian Refugees in Tanzania. JAMA, 283, 397-402. https://doi.org/10.1001/jama.283.3.397

[8] Yelland, J., Riggs, E., Small, R. and Brown, S. (2015) Maternity Services Are Not Meeting the Needs of Immigrant Women of Non-English Speaking Background: Results of Two Consecutive Australian Population Based Studies. Midwifery, 31, 664-670. https://doi.org/10.1016/j.midw.2015.03.001

[9] Small, R., Roth, C., Raval, M., Shafiei, T., Korfker, D., Heaman, M., McCourt, C. and Gagnon, A. (2014) Immigrant and Non-Immigrant Women's Experiences of Maternity Care: A Systematic and Comparative Review of Studies in Five Countries. BMC Pregnancy Childbirth, 14, 152. https://doi.org/10.1186/1471-2393-14-152

[10] Hynes, M., Sheik, M., Wilson, H.G. and Spiegel, P. (2002) Reproductive Health Indicators and Outcomes among Refugee and Internally Displaced Persons in Postemergency Phase Camps. JAMA, 288, 595-603.

https://doi.org/10.1001/jama.288.5.595

[11] Gibson-Helm, M., Teede, H., Block, A., Knight, M., East, C., Wallace, E.M. and Boyle, J. (2014) Maternal Health and Pregnancy Outcomes among Women of Refugee Background from African Countries: A Retrospective, Observational Study in Australia. BMC Pregnancy Childbirth, 14, 392. https://doi.org/10.1186/s12884-014-0392-0

[12] Bakken, K.S., Skjeldal, O.H. and Stray-Pedersen, B. (2017) Obstetric Outcomes of First- and Second-Generation Pakistani Immigrants: A Comparison Study at a Low-Risk Maternity Ward in Norway. Journal of Immigrant and Minority Health, 19, 33-40. https://doi.org/10.1007/s10903-015-0329-3

[13] Gibson-Helm, M., Boyle, J., Cheng, I.H., East, C., Knight, M. and Teede, H. (2015) Maternal Health and Pregnancy Outcomes among Women of Refugee Background from Asian Countries. International Journal of Gynecology and Obstetrics, 129, 146-151. https://doi.org/10.1016/j.ijgo.2014.10.036

[14] Shafiei, T., Small, R. and McLachlan, H. (2012) Women's Views and Experiences of Maternity Care: A Study of Immigrant Afghan Women in Melbourne, Australia. Midwifery, 28, 198-203. https://doi.org/10.1016/j.midw.2011.02.008

[15] Carrara, V.I., Hogan, C., De Pree, C., Nosten, F. and McGready, R. (2011) Improved Pregnancy Outcome in Refugees and Migrants despite Low Literacy on the Thai-Burmese Border: Results of Three Cross-Sectional Surveys. BMC Pregnancy Childbirth, 11, 45. https://doi.org/10.1186/1471-2393-11-45 


\section{List of Abbreviations}

UN: United Nations

IDP: Internally Displaced People

SPSS: Statistical Package for the Social Sciences

UNHCR: United Nations High Commissioner for Refugees

UNMISS: United Nations Mission in South Sudan 